\title{
Stenotrophomonas maltophilia flagellin induces a compartmentalized innate immune response in mouse lung
}

\author{
Ayaid Khadem Zgair and Sanjay Chhibber \\ Department of Microbiology, BMS Block, Panjab University, Chandigarh 160014, India
}

Correspondence

Sanjay Chhibber

chhibbersanjay@ymail.com

Received 2 March 2010

Accepted 14 May 2010

\begin{abstract}
Intranasal (i.n.) instillation of different amounts of purified Stenotrophomonas maltophilia flagellin preparation $(1,5$ and $15 \mu \mathrm{g})$ in BALB/c mice stimulated a transient innate immune response in the lungs. This was characterized by infiltration of different kinds of leukocytes (neutrophils, monocytes and lymphocytes), production of various inflammatory mediators (tumour necrosis factor alpha, interleukin 1 beta, interleukin 10, nitric oxide, myeloperoxidase and malondialdehyde) and activated alveolar macrophages (AMs). The proinflammatory cytokine production resulted in accumulation of activated neutrophils and macrophages and their products following immunostimulation with flagellin. The activation of AMs by flagellin was non-specific as AMs obtained from flagellin-treated animals, even after $4 \mathrm{~h}$ of exposure, were found to engulf and kill $S$. maltophilia and Staphylococcus aureus efficiently compared to macrophages obtained from control animals. i.n. instillation of $5 \mu \mathrm{g}$ flagellin resulted in the generation of an effective innate immunity compared to other flagellin doses. Our data provide strong evidence that S. maltophilia flagellin stimulates innate immunity in mouse lung.
\end{abstract}

\section{INTRODUCTION}

Stenotrophomonas maltophilia is an emerging pathogen that has been implicated in a variety of infections (Valdezate et al., 2004). The organism has been isolated with increasing frequency from hospitalized patients, as well as from those with immunosuppression (Senol, 2004; Talmaciu et al., 2002; Looney, 2005). It is also a common colonizer of the respiratory tract of patients with chronic lung disease (Pathmanathan \& Waterer, 2005). Adherence to the mucosal surface, which is mediated by flagella, has been considered as an important process in its colonization of the respiratory tract (Lillehoj et al., 2002). The flagellum is made up of a protein that has been characterized by a number of investigators (Chhibber \& Zgair, 2009).

Innate immunity serves as an essential first-line defence against microbial pathogens (Kaisho \& Akira, 2002), which may also influence the nature of subsequent adaptive immune responses. The accumulated evidence indicates that host cells involved in the innate immune response use the members of a relatively small family of structurally related membrane proteins termed Toll-like receptors (TLRs) (Sierro et al., 2001) to recognize and

Abbreviations: AM, alveolar macrophage; BAL, bronchoalveolar lavage; IL, interleukin; i.n., intranasal; MDA, malondialdehyde; MPO, myeloperoxidase; NO, nitric oxide; PMN, polymorphonuclear; TNF- $\alpha$, tumour necrosis factor alpha; TLR, Toll-like receptor. respond to products from diverse groups of bacterial, viral and fungal pathogens. The results of several recent studies demonstrate that flagellin from Gram-negative bacteria signals via TLR5 (Hayashi et al., 2001). As with other TLRs, flagellin signalling via TLR5 results in activation of the interleukin 1 receptor-associated kinase (Moors et al., 2001). Flagellin stimulates a variety of TLR5-positive cell types, including monocytes, macrophages, fibroblasts, and epithelial cells to produce cytokines such as tumour necrosis factor alpha (TNF$\alpha$ ), interleukin 1 (IL-1) and IL-8 (Sierro et al., 2001; Hayashi et al., 2001; Moors et al., 2001; Eaves-Pyles et al., 2001b), and nitric oxide (NO) in monocytes, macrophages and other resident cells, such as epithelial cells in the lungs. NO is an effecter molecule responsible for the killing of bacteria and other groups of pathogens (Moors et al., 2001; Tsai et al., 1997).

Many studies are available where it has been established that flagellin induces a systemic inflammatory response when administered intraperitoneally and intravenously (Hayashi et al., 2001; Eaves-Pyles et al., 2001a) and a local inflammatory response with intraintestinal administrated flagellin (Szabó, 2003; Sanders et al., 2006). The impact of flagellin on the innate and adaptive immunity in the lung is of utmost importance (Wolfgang et al., 2004; Yoon \& Mekalanos, 2008) so as to protect the host against infectious agents. In the present study, the potential of $S$. maltophilia flagellin to generate innate immunity in the mouse lung was explored. 


\section{METHODS}

Bacterial isolates. S. maltophilia (Sm2) and Staphylococcus aureus (Sa1) clinical strains were used in this study. Both the isolates are blood culture isolates. Bacteria were preserved by lyophilization and were routinely cultured at $37^{\circ} \mathrm{C}$ on Luria-Bertani agar plates. Subcultures were made every week.

Flagellin preparation and administration. Flagellin from $S$. maltophilia (Sm2) was isolated and purified according to the procedure described previously (Chhibber \& Zgair, 2009). LPS was removed from flagellin preparation by passing it through a polymyxin B column according to the manufacturer's instructions (Detoxin-Gel; Pierce) and as described by others (Moors et al., 2001). To determine the effects of flagellin on lung immunity, flagellin was instilled directly by the intranasal (i.n.) route. Different doses of soluble flagellin (1,5 and $15 \mu \mathrm{g})$ in a total volume of $50 \mu \mathrm{l}$ pyrogen-free PBS $(0.2 \mathrm{M}, \mathrm{pH} 7.2)$ were instilled intranasally in BALB/c mice (McDermott et al., 2000).

Animals. $\mathrm{BALB} / \mathrm{c}$ mice of $6-8$ week-old, weighing $20-25 \mathrm{~g}$ were procured from the central animal house of Panjab University, Chandigarh. Animals were kept in clean polypropylene cages and fed on a standard antibiotic-free diet (JBD Agencies, India). The study was conducted following approval from the animal ethics committee of Panjab University.

Experiment. The experimental group consisted of $48 \mathrm{BALB} / \mathrm{c}$ mice, divided into three subgroups depending on the flagellin dose $(1,5$ and $15 \mu \mathrm{g})$. The control group consisted of 12 mice that were given PBS (0.2 M, pH 7.2) intranasally. Four experimental group animals were sacrificed at each time point: $4 \mathrm{~h}, 12 \mathrm{~h}, 1$ day and 2 days after flagellin administration. In the control group, three animals were sacrificed at each time point. Lung tissue was sampled to determine bacterial numbers (c.f.u. $\mathrm{ml}^{-1}$ ), quantify inflammatory mediators, alveolar macrophage (AM) activity and histopathological changes in lung tissue.

Inflammatory and anti-inflammatory mediators. Whole lungs were weighed and then homogenized in $3 \mathrm{ml}$ lysis buffer containing $0.5 \%$ Triton X-100, $150 \mathrm{mM} \mathrm{NaCl}, 15 \mathrm{mM}$ Tris, $1 \mathrm{mM} \mathrm{MgCl}_{2}$ (pH 7.4) (Mohler et al., 2003).

Cytokine assays. TNF- $\alpha$, IL- $1 \beta$ and IL-10 levels were detected in lung homogenate supernatants of samples from control and immunized animals at different time intervals post-instillation of flagellin. Mouse ELISA kits were used to measure all the cytokines. IL$1 \beta$ (BD OptEIA; Becton Dickenson), IL-10 (Antigenix America) and TNF- $\alpha$ (Hunting sta. New York, USA) kits were used according to the manufacturer's instructions.

Myeloperoxidase (MPO). The standard method of Hirano (1996) was followed to check the MPO activity in lung homogenates.

Measurement of NO production. To confirm the NO production in the lungs, the NO reaction was measured in the form of nitrite levels in the lung homogenate by the colorimetric method of Tsai et al. (1997).

Malondialdehyde (MDA). MDA is a metabolite resulting from lipid peroxidation, which was detected by the method of Ohkawa et al. (1979).

Protein determination. Total protein content was checked in lung homogenate supernatant by Lowry method.

Phagocytosis. Phagocytosis was performed according to the method of Allen et al. (1987). Bacteria were harvested and resuspended in PBS $(0.2 \mathrm{M}, \mathrm{pH} 7.2)$ so as to obtain the optical density at $600 \mathrm{~nm}$ corresponding to $10^{5}$ c.f.u. $\mathrm{ml}^{-1}$. AMs were obtained according to the method described by Sugar et al. (1983) and they were resuspended in RPMI 1640 (High Media Laboratories). For uptake of bacteria, normal mouse serum, AMs suspension $\left(10^{4}\right.$ cells $\left.\mathrm{ml}^{-1}\right)$ and bacterial suspension $\left(10^{5}\right.$ c.f.u. $\left.\mathrm{ml}^{-1}\right)$ were taken, vortexed and incubated at $37{ }^{\circ} \mathrm{C}$ under $5 \% \mathrm{CO}_{2}$ atmosphere. Aliquots were taken regularly after 0,30 and $60 \mathrm{~min}$ incubation and centrifuged. The viable count of bacteria in the supernatant was determined by plating appropriate serial dilutions on nutrient agar plates. The results were expressed as the number of viable bacteria (c.f.u. $\mathrm{ml}^{-1}$ ) taken up by the AMs at the respective sampling time interval. For intracellular killing, bacterial suspension $\left(10^{5}\right.$ c.f.u. $\left.\mathrm{ml}^{-1}\right)$ was mixed with normal mouse serum and kept for $30 \mathrm{~min}$ at $37^{\circ} \mathrm{C}$. AMs $\left(10^{4} \mathrm{cells} \mathrm{ml}^{-1}\right)$ were added to the above bacterial suspension, incubated and centrifuged. The cells were lysed at different time intervals $(0,1,2$ and $3 \mathrm{~h})$. The bacterial colonies were counted after overnight incubation at $37{ }^{\circ} \mathrm{C}$ and expressed as c.f.u. $\mathrm{ml}^{-1}$.

Bronchoalveolar lavage (BAL) cell counts. The total cell count in BAL specimens was measured using a haemocytometer. The differential count of the cells was determined by examining smears stained with Leishman stain (Skerrett et al., 2007).

Histology. Formalin-fixed, paraffin-embedded lung sections prepared from lungs obtained at different time intervals $(4 \mathrm{~h}, 12 \mathrm{~h}, 1$ day and 2 days) were stained with haematoxylin and eosin and examined for histopathological changes (Medan et al., 2002).

Statistical analysis. All values have been used to give a mean value and the standard deviation calculated. The differences were analysed by using Student's $t$-test employing Origin version 8.0 software. A value of $P<0.05$ was considered to be statistically significant.

\section{RESULTS}

\section{Cytokine production post-instillation of flagellin}

The levels of IL- $1 \beta$, TNF- $\alpha$ and IL-10 were estimated in the lung homogenates following instillation of different concentrations of flagellin (1,5 and $15 \mu \mathrm{g})$. As shown in Fig. 1(a), flagellin induced IL- $1 \beta$ production in the lung as early as $4 \mathrm{~h}$ post-instillation, with a peak level occurring around $12 \mathrm{~h}$. A similar trend was observed in case of TNF- $\alpha$ in the lung homogenates (Fig. 1b). Flagellin at a concentration of $5 \mu \mathrm{g}$ was found to be the best inducer of proinflammatory cytokines, whereas a higher concentration suppressed their production. Flagellin also stimulated production of IL-10, which was delayed compared to proinflammatory cytokines (TNF- $\alpha$ and IL-1 $\beta$ ). The results in Fig. 1(c) show that there was an increase in the levels of IL-10 with time and maximum production was seen at $24 \mathrm{~h}$ post-instillation, the levels remained almost constant thereafter until $48 \mathrm{~h}$.

\section{MPO, MDA and NO production in mice lungs}

The MPO levels in the lung homogenates are summarized in Fig. 2(a). The MPO levels increased with time and the maximum level was achieved on exposure to $5 \mu \mathrm{g}$ flagellin at $24 \mathrm{~h}$ post-instillation.

The lipid peroxidation was assessed on the basis of MDA estimation. Fig. 2(b) shows the time-course of changes in the MDA levels in lung homogenates, MDA levels 
(a)

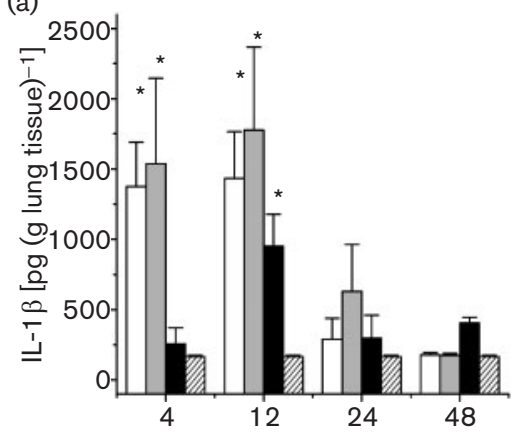

(b)

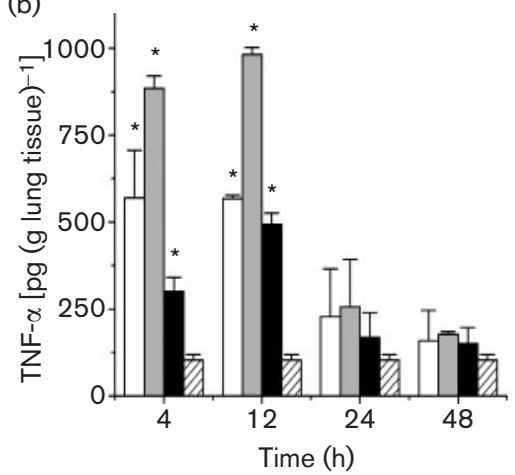

(c)

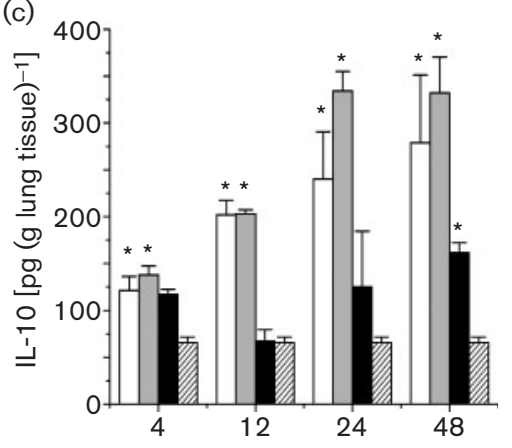

Fig. 1. Time-course of changes in IL-1 $\beta$ (a), TNF- $\alpha$ (b) and IL-10 (c) concentrations in lung homogenates following i.n. instillation of different concentrations of S. maltophilia flagellin: $0 \mu \mathrm{g}$ (PBS control) (hatched bars), $1 \mu \mathrm{g}$ (white bars), $5 \mu \mathrm{g}$ (grey bars) and $15 \mu \mathrm{g}$ (black bars). Asterisks indicate a significant difference from the control group.

increased dramatically post-instillation of flagellin with the peak at $24 \mathrm{~h}$. Similar levels were achieved with all the three different concentrations of flagellin.

The time-course of changes in the nitrite levels, postinstillation of flagellin $(1,5$ and $15 \mu \mathrm{g})$ is shown in Fig. 2(c). Flagellin instillation stimulated the production of NO, the level of NO increased with time and the highest level was achieved at $24 \mathrm{~h}$. All different concentrations of flagellin were found to stimulate NO production.

\section{Leukocyte infiltration in the lungs following instillation of flagellin}

Fig. 3 shows the number of different leukocytes (neutrophils, lymphocytes and monocytes) enumerated in the BAL fluid after i.n. instillation of different concentrations of flagellin. An increase in their count was observed following instillation of flagellin, with the maximum number seen at $24 \mathrm{~h}$ postinstillation, the number of which then declined at $48 \mathrm{~h}$.

\section{Histopathological examination of the lungs}

The lungs obtained from mice that were intranasally instillated with $5 \mu \mathrm{g}$ flagellin were sectioned and examined microscopically. The results in Fig. 4 show that no immediate cell infiltration was observed post-exposure to flagellin as the results were comparable with that of control. The infiltration by polymorphonuclear (PMN) cells started at $12 \mathrm{~h}$ but the maximum infiltration was observed at $24 \mathrm{~h}$ post-instillation of flagellin. PMN cells were observed around blood vessels indicating PMN cells infiltrated from the blood vessels. No collapse of bronchi and blood vessel walls was observed.

\section{Activation of AMs following exposure to flagellin}

AMs were isolated from mice at different time intervals (4, 12, 24 and $48 \mathrm{~h}$ ) post-instillation of different concentrations of flagellin. Fig. 5 shows the mean bacterial uptake by AMs in vitro. These activated macrophages engulfed both $S$. maltophilia as well as Staphylococcus aureus with equal (a)

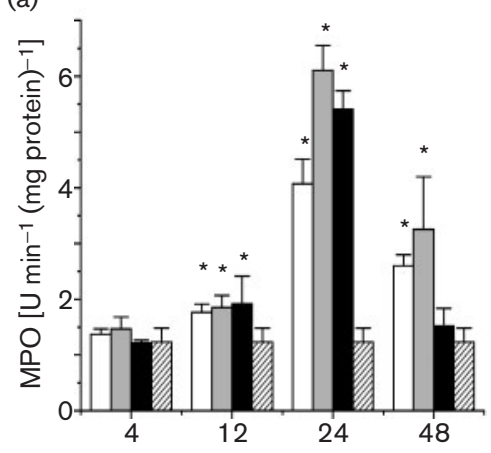

(b)

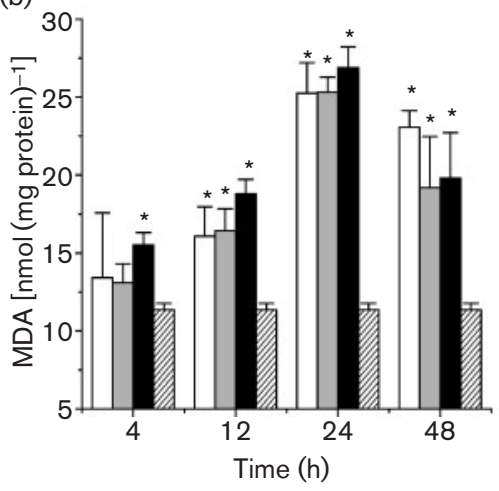

(c)

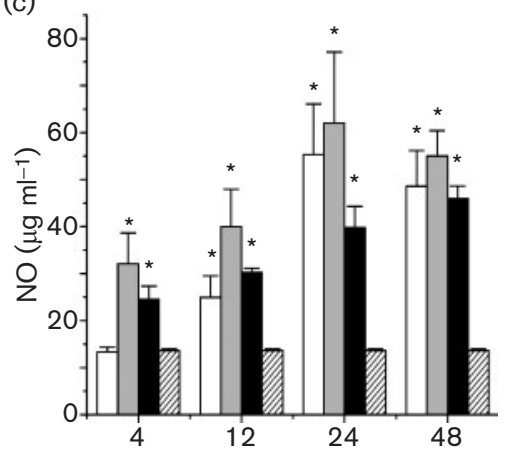

Fig. 2. Time-course of changes in MPO (a), MDA (b) and NO (c) levels in lung homogenates following i.n. instillation of different concentrations of $S$. maltophilia flagellin: $0 \mu \mathrm{g}$ (PBS control) (hatched bars), $1 \mu \mathrm{g}$ (white bars), $5 \mu \mathrm{g}$ (grey bars) and $15 \mu \mathrm{g}$ (black bars). Asterisks indicate a significant difference from the control group. 

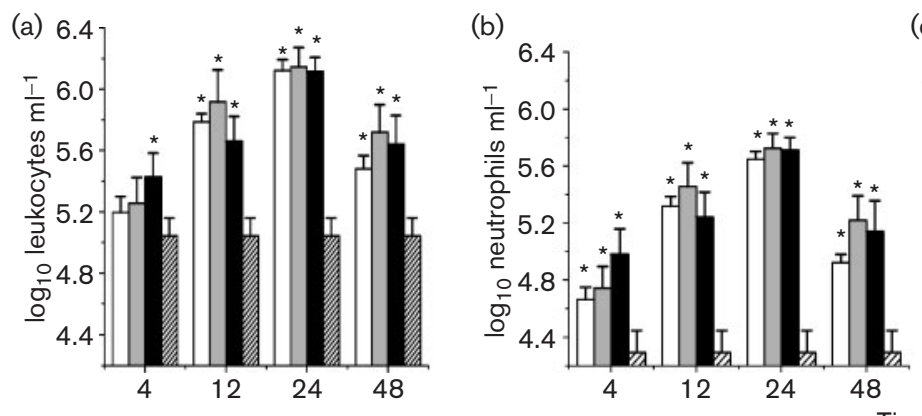

(c)

(d)
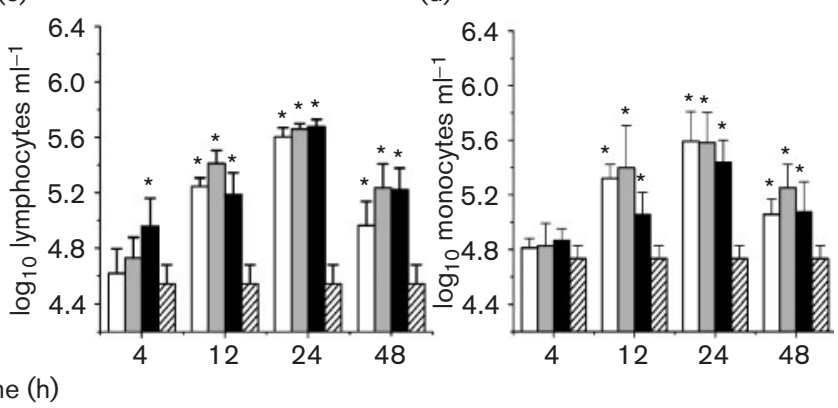

Fig. 3. Time-course of the number of leukocytes - total leukocytes (a), neutrophils (b), lymphocytes (c) and monocytes (d) - in the BAL of BALB/c mice following i.n. instillation of different concentrations of S. maltophilia flagellin: $0 \mu \mathrm{g}$ (PBS control) (hatched bars), $1 \mu \mathrm{g}$ (white bars), $5 \mu \mathrm{g}$ (grey bars) and $15 \mu \mathrm{g}$ (black bars). Asterisks indicate a significant difference from the control group.

efficiency. Non-specific activation of AMs was seen as early as $4 \mathrm{~h}$ post-instillation of flagellin, which declined gradually. The minimum uptake of bacteria was observed by AMs obtained after $48 \mathrm{~h}$ of flagellin exposure. On comparison of the data with control data, significant uptake was seen with all the three different concentrations of flagellin used in this study, but maximum activation was seen on treatment with $5 \mu \mathrm{g}$ flagellin.

The results of surviving bacteria within AMs are presented in Fig. 6. Enhanced killing of both the bacteria (Staphylococcus aureus and S. maltophilia) was seen

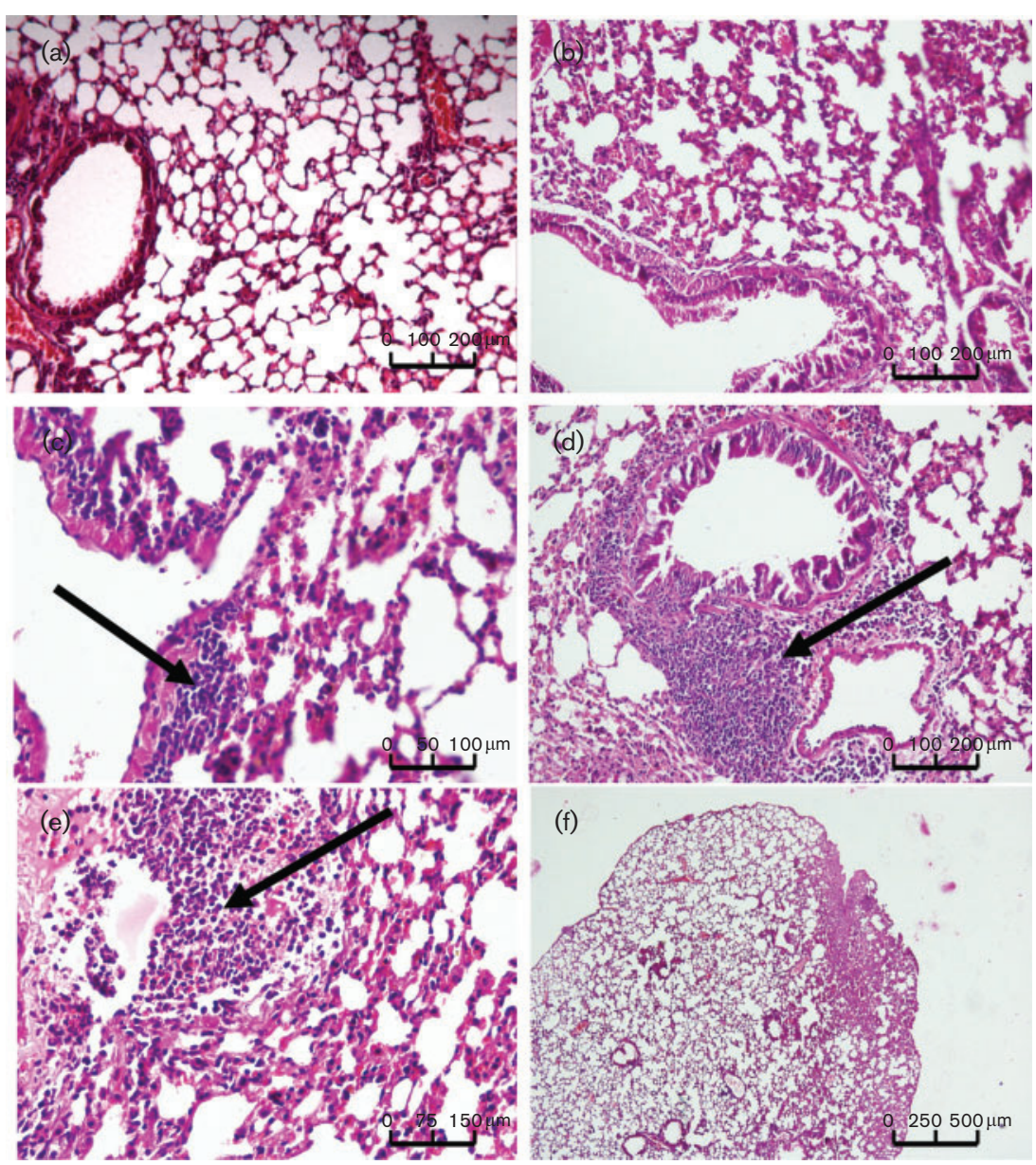

Fig. 4. $P M N$ cell infiltration following instillation of $5 \mu \mathrm{g} S$. maltophilia flagellin in the lungs of BALB/c mice. Lungs sections were prepared and stained for histological analysis with haematoxylin and eosin. (a) Control section from a mouse receiving only PBS (bar, $200 \mu \mathrm{m}$ ). (b) Section taken at $4 \mathrm{~h}$ after flagellin instillation (bar, $200 \mu \mathrm{m}$ ). (c) Section taken at $12 \mathrm{~h}$ after flagellin instillation showing a little cluster of leukocytes, indicated by an arrow (bar $100 \mu \mathrm{m})$. ( $\mathrm{d}$ and e) Sections were taken at $24 \mathrm{~h}$ after flagellin instillation. Leukocyte infiltration around blood vessels and bronchi involved predominantly neutrophils and lymphocytes, indicated by an arrow [bars, $200 \mu \mathrm{m}$ and $150 \mu \mathrm{m}$ in (d) and (e), respectively]. (f) A section taken at $48 \mathrm{~h}$ shows very little infiltration and no collapsed alveoli (bar, $500 \mu \mathrm{m}$ ). In all sections the bronchi, alveoli and blood vessels were almost normal. 


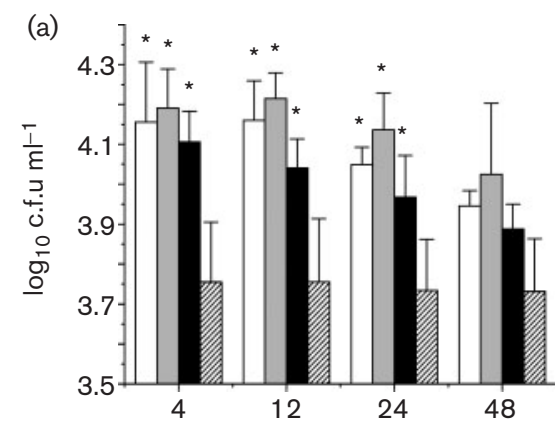

(b)

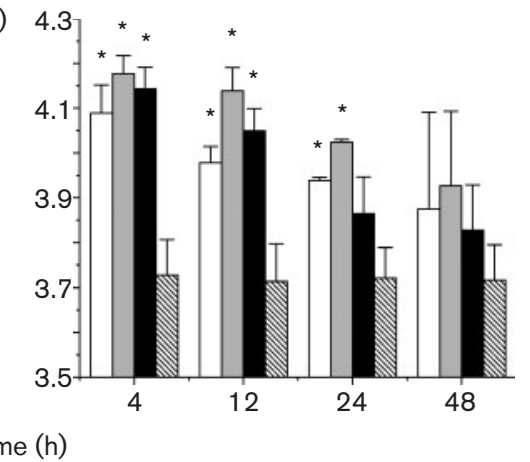

Fig. 5. The kinetics of (a) S. maltophilia and (b) Staphylococcus aureus uptake by AMs obtained from animals instilled with 1,5 and $15 \mu \mathrm{g}$ flagellin. AMs were collected at different time intervals $(4,12,24$ and $48 \mathrm{~h})$ following instillation of different concentrations of S. maltophilia flagellin - $0 \mu \mathrm{g}$ (PBS control) (hatched bars), $1 \mu \mathrm{g}$ (white bars), $5 \mu \mathrm{g}$ (grey bars) and $15 \mu \mathrm{g}$ (black bars) flagellin - and exposed to bacteria in vitro.

compared to controls. Increased killing by AMs obtained from flagellin-exposed animals was seen as early as $4 \mathrm{~h}$ post-instillation of flagellin. The maximum killing of bacteria was seen by AMs obtained from animals immunized with $5 \mu \mathrm{g}$ flagellin at all time points.

\section{DISCUSSION}

Resistance to infection in vertebrates relies on a complex interaction between two separate but complementary arms of the immune system: adaptive immunity and innate immunity. Flagellin responses form an important bridge between these two immune responses, which explains the unique properties of flagellin as an immunogen. In this study we checked the activation of the innate immune response in the lungs of $\mathrm{BALB} / \mathrm{c}$ mice on exposure to flagellin obtained from $S$. maltophilia. Administration of $S$. maltophilia flagellin intranasally resulted in the generation of local immunity within the lungs. Resident AMs constitute the first line of defence against invaders in the lungs and exposure to flagellin resulted in their activation as enhanced macrophage uptake and killing of bacteria was observed. Two different mechanisms of macrophage activation have been proposed. One is the classical pathway that provides contact of macrophages with bacterial antigens like flagellin. This contact is mediated by specific receptors on AMs like TLR5, Naip5 and Ipaf (Chen \& Pedra, 2010). The other process includes activation of cytokines like IL4 and IL-13 (Stein et al., 1992; Doherty et al., 1993). Once activated, macrophages stimulate the production of proinflammatory cytokines such as TNF- $\alpha$ and IL- $1 \beta$ (Henderson et al., 1996), and several other chemokines such as IL-8/CXCL8, IP-10/CXCL10, MIP-1 $\alpha /$ CCL3 and MIP-1//CCL4, which may act as chemoattractants for neutrophils, immature dendritic cells, natural killer cells and activated $\mathrm{T}$ cells (Luster, 2002). The neutrophil infiltration in lungs seen after flagellin treatment confirmed the involvement of one or more of these chemoattractants (Honko \& Mizel, 2004). The raised levels of proinflammatory cytokines (IL-1 $\beta$ and TNF- $\alpha$ ) during initial exposure to flagellin led to activation of neutrophils and macrophages in the lung tissue, which resulted in a higher level of NO production (Liew, 1995). In a recent study, the clearance of $S$. maltophilia in the lung of DBA/2 mice was correlated with an early and intense bronchial and alveolar inflammatory response primarily generated by neutrophils (Di Bonaventura et al., 2010).

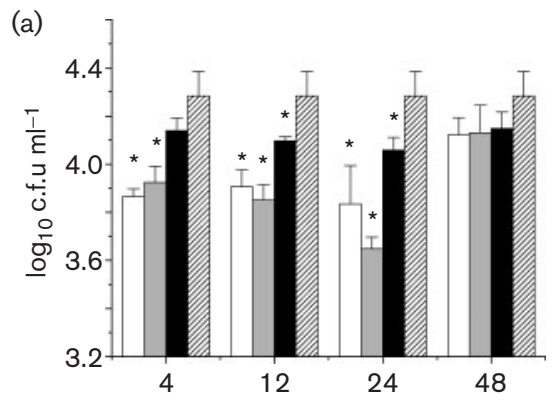

(b)

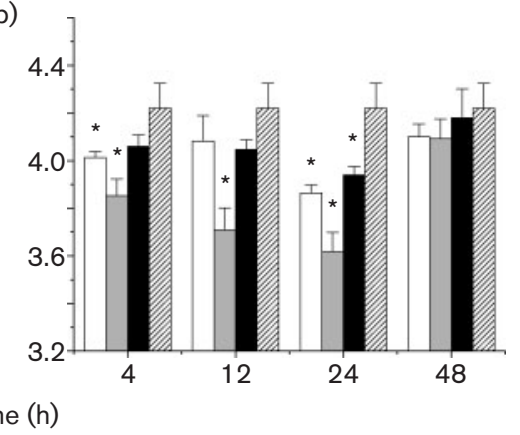

Fig. 6. Number of bacteria surviving within the AMs. AMs from mice treated with 1,5 and $15 \mu \mathrm{g}$ flagellin and collected at different time intervals $(4,12,24$ and $48 \mathrm{~h})$ post-treatment were exposed to $S$. maltophilia (a) or Staphylococcus aureus (b) in vitro and then lysed to check bacteria surviving within the macrophages. $0 \mu \mathrm{g}$ (PBS control) (hatched bars); $1 \mu \mathrm{g}$ (white bars); $5 \mu \mathrm{g}$ (grey bars); $15 \mu \mathrm{g}$ (black bars) flagellin. 
NO is a major source of immunomodulation, and is produced by the enzyme nitric oxide synthase type 2 (NOS2) in the AMs and monocytes. Several animal models have been used to demonstrate the role of $\mathrm{NO}$ as an effecter molecule for killing bacteria and other pathogens (Tsai et al., 1997). NO also prolongs the ability of human dendritic cells to internalize antigens at the site of inflammation, leading to modulation of the first step leading to antigen-specific immune responses (Paolucci et al., 2000). An increase in NO production in the lungs on exposure to flagellin is suggestive of enhanced antibacterial immunity, which can be helpful in clearing the pathogen from the lungs and thus afford protection to the host against infection.

A negative relation was seen between IL-10 production and proinflammatory cytokines (IL- $1 \beta$ and TNF- $\alpha$ ). IL-10 has been shown to play a counterproductive effect on the immune system as overproduction of IL-10 decreases the harmful effects of proinflammatory cytokines. Thus production of IL-10 along with activation of AMs not only cleared the bacteria from the lungs but also protected the tissue from damage due to an exaggerated immune response. This was confirmed on the histopathological examination of lung tissue following flagellin treatment as no serious damage was observed in the lung sections made at different time intervals. The finding also negated the concern about raised MDA levels in the lung tissue as MDA is an indicator of peroxidation of fatty acids due to free radical (oxygen) generation. The histopathological results suggest that the resultant effect was weak and hence flagellin exposure resulted in an immune response that did not show any damage to the host tissue.

In conclusion, our data provide strong evidence that $S$. maltophilia flagellin stimulates innate immunity, which may clear the organisms during pulmonary infection by phagocytosis. These results confirm that flagellin can be used as a protective molecule against infection with $S$. maltophilia especially in a debilitated host, and further work on these lines is in progress in our laboratory.

\section{REFERENCES}

Allen, P. M., Fisher, D., Saunders, J. R. \& Hart, C. A. (1987). The role of capsular polysaccharide $\mathrm{K} 2 \mathrm{lb}$ of Klebsiella and of the structurally related colonic-acid polysaccharide of Escherichia coli in resistance to phagocytosis and serum killing. J Med Microbiol 24, 363-370.

Chen, G. \& Pedra, J. H. F. (2010). The inflammasome in host defense. Sensors 10, 97-111.

Chhibber, S. \& Zgair, A. K. (2009). Involvement of Stenotrophomonas maltophilia flagellin in bacterial adhesion to airway biotic surfaces: an in vitro study. Am J Biomed Sci 1, 188-195.

Di Bonaventura, G., Pompilio, A., Zappacosta, R., Petrucci, F., Fiscarelli, E., Rossi, C. \& Piccolomini, R. (2010). Role of excessive inflammatory response to Stenotrophomonas maltophilia lung infection in DBA/2 mice and implications for cystic fibrosis. Infect Immun 78, 2466-2476.
Doherty, T. M., Kastelein, R., Menon, S., Andrade, S. \& Coffman, R. L. (1993). Modulation of murine macrophage function by IL-13. J Immunol 151, 7151-7160.

Eaves-Pyles, T., Murthy, K., Liaudet, L., Virág, L., Ross, G., Soriano, F. G., Szabó, C. \& Salzman, A. L. (2001a). Flagellin, a novel mediator of Salmonella-induced epithelial activation and systemic inflammation: $\mathrm{I} \kappa \mathrm{B} \alpha$ degradation, induction of nitric oxide synthase, induction of proinflammatory mediators, and cardiovascular dysfunction. J Immunol 166, 1248-1260.

Eaves-Pyles, T. D., Wong, H. R., Odoms, K. \& Pyles, R. B. (2001b). Salmonella flagellin-dependent proinflammatory responses are localized to the conserved amino and carboxyl regions of the protein. J Immunol 167, 7009-7016.

Hayashi, F., Smith, K. D., Ozinsky, A., Hawn, T. R., Yi, E. C., Goodlett, D. R., Eng, J. K., Akira, S., Underhill, D. M. \& Aderem, A. (2001). The innate immune response to bacterial flagellin is mediated by Toll-like receptor 5. Nature 410, 1099-1103.

Henderson, B., Poole, S. \& Wilson, M. (1996). Bacterial modulins: a novel class of virulence factors which cause host tissue pathology by inducing cytokine synthesis. Microbiol Rev 60, 316-341.

Hirano, S. (1996). Migratory responses of PMN after intraperitoneal and intratracheal administration of lipopolysaccharide. Am J Physiol 270, L836-L845.

Honko, A. N. \& Mizel, S. B. (2004). Mucosal administration of flagellin induces innate immunity in the mouse lung. Infect Immun 72, 66766679.

Kaisho, T. \& Akira, S. (2002). Toll-like receptors as adjuvant receptors. Biochim Biophys Acta 1589, 1-13.

Liew, F. Y. (1995). Interactions between cytokines and nitric oxide. Adv Neuroimmunol 5, 201-209.

Lillehoj, E. P., Kim, B. T. \& Kim, K. C. (2002). Identification of Pseudomonas aeruginosa flagellin as an adhesion for Mucl mucin. Am J Physiol Lung Cell Mol Physiol 282, L751-L756.

Looney, W. J. (2005). Role of Stenotrophomonas maltophilia in hospital-acquired infection. Br J Biomed Sci 62, 145-154.

Luster, A. D. (2002). The role of chemokines in linking innate and adaptive immunity. Curr Opin Immunol 14, 129-135.

McDermott, P. F., Ciacci-Woolwine, F., Snipes, J. A. \& Mizel, S. B. (2000). High affinity interaction between gram-negative flagellin and a cell surface polypeptide results in human monocyte activation. Infect Immun 68, 5525-5529.

Medan, D., Wang, L., Yang, X., Dokka, S., Castranova, V. \& Rojanasakul, Y. (2002). Induction of neutrophil apoptosis and secondary necrosis during endotoxin-induced pulmonary inflammation in mice. J Cell Physiol 191, 320-326.

Mohler, J., Azoulay-Dupuis, E., Amory-River, C., Mazoit, J. X., Bedos, J. P. P., Rieux, V. \& Moine, P. (2003). Streptococcus pneumoniae straindependent lung inflammatory responses in a murine model of pneumonia. Intensive Care Med 29, 808-816.

Moors, M. A., Li, L. \& Mizel, S. B. (2001). Activation of interleukin-1 receptor associated kinase by Gram-negative flagellin. Infect Immun 69, 4424-4429.

Ohkawa, H., Ohishi, N. \& Yagi, K. (1979). Assay for lipid peroxides in animal tissues by thiobarbituric acid reaction. Anal Biochem 95, 351-358.

Paolucci, C., Rovere, P., De Nadai, C., Manfredii, A. A. \& Clementi, E. (2000). Nitric oxide inhibits the tumor necrosis factor $\alpha$-regulated endocytosis of human dendritic cells in a cyclic GMP-dependent way. J Biol Chem 275, 19638-19644.

Pathmanathan, A. \& Waterer, G. W. (2005). Significance of positive Stenotrophomonas maltophilia culture in acute respiratory tract infection. Eur Respir J 25, 911-914. 
Sanders, C. J., Yu, Y., Moore, D. A., Williams, I. R. \& Gewirtz, A. T. (2006). Humoral immune response to flagellin requires $T$ cells and activation of innate immunity. J Immunol 177, 2810-2818.

Senol, E. (2004). Stenotrophomonas maltophilia: the significance and role as a nosocomial pathogen. J Hosp Infect 57, 1-7.

Sierro, F., Dubois, B., Coste, A., Kaiserlian, D., Kraehenbuhl, J. P. \& Sirard, J. C. (2001). Flagellin stimulation of intestinal epithelial cells triggers CCL20-mediated migration of dendritic cells. Proc Natl Acad Sci U S A 98, 13722-13727.

Skerrett, S. J., Wilson, C. B., Liggitt, H. D. \& Hajjar, A. M. (2007). Redundant Toll-like receptor signaling in the pulmonary host response to Pseudomonas aeruginosa. Am J Physiol Lung Cell Mol Physiol 292, L312-L322.

Stein, M., Keshav, S., Harris, N. \& Gordon, S. (1992). Interleukin 4 potently enhances murine macrophage mannose receptor activity: a marker of alternative immunologic macrophage activation. J Exp Med 176, 287-292.

Sugar, A. M., Brummer, E. \& Stevens, D. A. (1983). Murine pulmonary macrophages: evaluation of lung lavage fluids, miniaturized monolayers, and candidacidal activity. Am Rev Respir Dis 127, $110-112$.
Szabó, C. (2003). Role of flagellin in the pathogenesis of shock and acute respiratory distress syndrome: therapeutic opportunities. Crit Care Med 31, S39-S45.

Talmaciu, I., Ren, C. L., Kolb, S. M., Hickey, E. \& Panitch, H. B. (2002). Pulmonary function in technology-dependent children 2 years and older with bronchopulmonary dysplasia. Pediatr Pulmonol 33, 181-188.

Tsai, W. C., Strieter, R. M., Zisman, D. A., Wilkowski, J. M., Bucknell, K. A., Chen, G. H. \& Standiford, T. J. (1997). Nitric oxide is required for effective innate immunity against Klebsiella pneumoniae. Infect Immun 65, 1870-1875.

Valdezate, S., Vindel, A., Martin-Davila, P., Del Saz, B. S., Baquero, F. \& Canton, R. (2004). High genetic diversity among Stenotrophomonas maltophilia strains despite their originating at a single hospital. J Clin Microbiol 42, 693-699.

Wolfgang, M. C., Jyot, J., Goodman, A. L., Ramphal, R. \& Lory, S. (2004). Pseudomonas aeruginosa regulates flagellin expression as part of a global response to airway fluid from cystic fibrosis patients. Proc Natl Acad Sci U S A 101, 6664-6668.

Yoon, S. S. \& Mekalanos, J. J. (2008). Decreased potency of the Vibrio cholerae sheathed flagellum to trigger host innate immunity. Infect Immun 76, 1282-1288. 